SHS Web of Conferences 12, 01012 (2014)

DOI: $10.1051 /$ shsconf/ 20141201012

(C) Owned by the authors, published by EDP Sciences, 2014

\title{
Disaster Preparedness of Hotel Industry Abroad: A Comparative Analysis
}

\author{
Ahmad R. AlBattat ${ }^{1}$, Ahmad Puad Mat Som ${ }^{2}$ \\ ${ }^{1,2}$ School of Housing, Building and Planning, Universiti Sains Malaysia, 11800, Penang, Malaysia \\ ${ }^{1,2}$ Sustainable Tourism Research Cluster, Universiti Sains Malaysia, 11800, Penang, Malaysia
}

\begin{abstract}
This paper aims to identify major emergencies that have the potential to place hotels in emergency and disaster situations; investigate how hotels were prepared for emergencies, how they manage and overcome emergencies when occurred; and limitations and factors influencing successful emergency planning and adoption emergency management in Malaysian and Jordanian hotels. Face-to-face interview for managers from three, four and five star hotels from different backgrounds: local; regional; and International in Kuala Lumpur, Penang, Amman and Petra were undertaken. Results revealed that hotels are exposed to a wide range of natural and man-made disasters, Occurred globally affected locally. Hotels lack proactive emergency planning and a lot of constraints which impede successful emergency planning for disasters in the hotel industry, with emphasizing on the relevant authority's role to demonstrate emergency management to hotels convincing them to adopt such practices, so they can be able to cope with emergencies effectively.
\end{abstract}

\section{Introduction}

Disasters experienced by hospitality industry have steadily increased over the past few decades. Disaster management has become an important issue as hospitality key players seek ways to cope with these unexpected events, which confound threats to the viability of hospitality organizations [1], and create multiple challenges for the private and public sectors [2]. Kash and Darling [3] pointed out that the core of the resolution of a disaster is in the evaluating the current level of disaster planning and preparedness in the hospitality industry, and examining the relationship between organizational factors (type, size, and age), disaster planning activities and disaster preparedness.

A wave of catastrophic events struck the hospitality industry in recent years, increasing the awareness among emergency managers and scholars on how to read, manage, and overcome the impact of emergencies on the hospitality industry [4]. Gheytanchi, Joseph [5] identified the major failure when dealing with disasters and emergencies. Other scholars explain how hospitality industry could benefit from emergency management to prevent losses and mitigate negative impact of media on affected destinations [6]. Perry and Quarantelly [7] defined the disaster as "an extreme event with a natural, technological or social cause that has consequences in term of casualties, and disruptive events which threaten people, properties, and environment and which requires a coordinated and rapid response". 
These emergency situations have been classified into natural and man-made disasters; natural disasters caused by nature, such as floods, tsunamis, typhoons, and often termed "act of God". While, man-made disasters are known as socio-technical disasters which could occur in four types: technical disasters, transport failure, stadia failure, and production failure [8].

The Jordanian hotels have experienced a wave of disasters and emergencies in the last two decades. Overall, the period from 2000 to date has been affected by natural and man-made disasters, with political instability in the Middle East which influence Jordanian hotels negatively [9]. Since September 11, 2001, at least 18 major terrorist incidents targeted hospitality industry worldwide, including two conducted in Jordan [10]. While, the Malaysian hotels were not immune from several disasters affecting Southeast Asia, arising broadly outside Malaysia with deep impact on hotels. This research aims to identify major emergencies that occurred in the hotel industry; investigating hotels preparation for emergencies in the past; and exploring how hotels manage and overcome such emergencies; and limitations that hotels encountered.

\section{Literature review}

\subsection{Emergency and hospitality industry}

Jordan located in the heart of Middle East, Southwest Asia. The majority of the population lives in urban areas. As a modern, low-middle income country, with limited resources, and semi-arid climate, Jordan is subjected to several threats affecting the economic, social, and state structures of the country and hospitality industry, which make it vulnerable to emergencies such as flash floods, earthquakes, epidemics, drought [11] Other emergencies such as; extreme temperature, windstorm, locusts, manmade emergencies such as terrorist attacks, chemical, biological, and radioactive contamination, armed conflict and mass population migrations [12].

In the other hand, geographically Malaysia is outside the Pacific edge of the fire and comparatively free from any pillage and destruction caused by natural disasters such as earthquake, volcano, and typhoons. But it's subjected to monsoon floods, landslides, and severe haze. During the period of 1968-2004 Malaysia has experienced 39 disasters, classified as natural, man-made, and subsequent disasters, caused 1,742 deaths and 2,713 injuries [13]. The matter raises the need for setting up for advanced warning systems, forecast future disasters, and effective disaster management in order to reduce the effect of such disasters on the hospitality industry [14].

The hospitality industry is one of the most vulnerable industries for emergencies. Emergencies become more frequent and complex than before [18], affecting the hospitality industry and related industries [19]. Whether it is man-made or natural disasters, it is very important to be well prepared to mitigate the impact of emergencies and minimize losses. With no doubt that safety and security are two of the most important issues of the guests. Rittichainuwat [20] asserted that low-cost destination couldn't motivate tourists to visit, especially hazardous destinations. Organizations should establish cross role between media and government authorities to avoid unnecessary information, and transmit a clear message to avoid ambiguity [21].

Hotels as a risky business receiving employees and guests from different nations and cultures, with a tendency for disasters and emergencies to occur and cause unwanted damages [15]. Scholars discussed the impact of terrorism on the tourism industry and argued that terrorism and instability have a considerable bad effect on tourism industry [10]. Ichinosawa [16] explored the impacts of natural disasters on tourism industry and argued that such event will disturb the destination with a bad impact on local community, stakeholders, and economy. Cashman, Cumberbatch [17] argued that globalization and over development cause a very bad changing in the world and habitats, with greater impact on hotels and tourism business. 


\subsection{Disasters and emergency management}

The last few decades have witnessed a considerable increment in the number, scope and complexity of disasters and emergencies. Helsloot and Ruitenberg [22] explain differences between emergency planning and preparedness, asserted that differences come from the practices, and planning should be the standard of preparedness. Alexander [23] defined the emergency planning as a coordinated set of protocols for managing disastrous event. Even though, each emergency is unique, but with common ground between them it will be easier to forecast and plan for it. Therefore, it's very important to attract more attention to hospitality emergency management, and the planning process to manage, overcome, and recover from emergencies [24].

The quality of emergency planning should be monitored, evaluated, and improved for several reasons. First, emergency management is not yet a fully-fledged profession [25], with a lack of adequate training and specialist knowledge for emergency planners. Second, inefficiency in emergency planning raises the mismatches between the procedures and available resources in balance with chronic emergency needs. Third, emergency planning should be a dynamic continuous process, since it's become static it will be mutated to become dysfunctional [26]. Paton [27] argued that emergency planning is not a continuous process and to be regarded to be ended by itself. Alexander [24] defends this statement and argued that it should be dynamically processed to insure functionality. Planning by hotels should be in collaboration with local authorities to bridge the gap between internal and external plans [28]. Fourth, informal planning which contains vague definition of responsibilities and procedures, and poorly indicated [29]. Finally, emergency plans shouldn't be isolated from presiding laws and regulations. Scholars have noted that emergency planning should in a multi organizational nature [26]. Good plans and teams are essential requirements for surviving from disasters. Hard work and many difficult decisions are very important in the case of emergency recovery. From the end of post-emergency period until the reestablishment of the trend line emergency recovery involves all effort to deal, manage and recover from the disastrous situation.

\section{Methodology}

This comparative study aims to investigate emergency planning and preparedness, and the impact of emergencies and disasters on the tourism and hospitality industry in Jordan as a part of Middle East region and Malaysia as a part of South Asia region. Both countries are safe and stable, surrounding by unstable countries which affect the hotel industry. To undertake this study, a qualitative research methodology was considered the most appropriate method to describe the existing issues related to disasters and emergencies affecting hotels [30]. Secondary information was assembled from governmental resources, while in the qualitative approach, semi-structured face-to-face interviews have been used [31], with a number of pre-determined questions, facilitated the scientific comparison between the responses of participating interviewees [32]. 43 key persons in charge of 36 Jordanian hotels, and 33 Malaysian hotels, rated three, four, and five star hotels were interviewed [33]; this sample was selected using the purposeful snowball method. Regarding this method, personal links were used to identify the most knowledgeable persons. The sample size was determined using the 'saturation criterion' [34] The materials collected in this study were subjected to manually qualitative thematic analysis aiming to uncover the prevalent themes by identifying, describing and reporting the content of data. Results will be outlined next, featuring direct quotations to support the study's findings. 


\section{Findings and discussion}

\subsection{General information}

Respondents were from the top management in hotels rated three, four, and five star hotels. The interview period lasts from 13:31 to 1:20:00 minutes. And 100 percent of respondents clarified that their hotels have experienced emergencies and disasters in the last two decades.

\subsection{Emergencies facing hotels}

- Respondents were requested to explain the types and magnitude of emergencies that occurred in their hotels in the past.

The findings revealed that Jordanian hotels were threatened by several emergencies and political instability in the Middle East. The findings also showed that terrorism, Amman bombings 2005, Libyan patient's profile, financial problems, tax, pandemics, employee turnover, and natural threats were identified as major emergencies facing Jordanian hotels. This finding shows that the hotels have generally been more vulnerable to a wide range of disasters and emergencies and highly susceptible to it. This is consistent with Paraskevas and Arendell [10], and Ritchie [35] findings who argued that the unstable global tourism environment result in making hospitality organizations highly vulnerable to disasters and emergencies.

The findings also revealed that Malaysian hotels had been affected by several local, regional, and global disasters. Disasters classified as disease, terrorism, natural, and economic disaster. Respondents agreed that disasters arising broadly outside Malaysia, with a deep impact on hotel industry. There were differences among respondents in perceived impact, depending upon the scale, size of business, and stricken destinations. During the SARS outbreak, hotels received a formidable shock and International arrivals reduced by $20 \%$ in some states. Approximately, all respondents emphasized that SARS and avian flu created the intricate situation and "it took us more than six months to recover". In line with epidemics, tourist arrivals fluctuated in Malaysia and surrounded region regarding the first Bali bombing in 2002, and the second Bali bombing 2005. "Though it occurred in Indonesia but it affects Malaysian hospitality industry". Furthermore, the bad impact of media.

According to respondents, the deep impact of the Asian tsunami caused losses estimated at around RM30 million (US\$8 million) in Penang and other northern states. Some hotels and beach resorts suffered a lot from dropping tourist arrivals for a short period of time. The hospitality industry also has been affected by the global economic crisis and the outbreak of H1N1 in 2008 and 2009. The key respondents claimed that the severe impact was due to reservation cancellation, reducing the length of stay with less expenditure from tourists. This situation affects not only hotels but all key players in tourism business, airlines, and tour operators. Senior managers emphasized that dramatic drop in hotel occupancy rates has been experienced, With less spending on leisure, shopping, food and beverage, especially SMEs who clarifies that they were "unable to cope with disaster without financial support". Hospitality industry also has been suffering from "the drop in tour packages" from the western markets from USA and Canada, Scandinavian countries, west and central Europe, Australia and New Zealand as respondent answers. Respondent raise a very important issue mentioned that more tourists come from Middle-East region in the last two years. This will give indications that the Middle-East revolutions created opportunities for Malaysia to attract more tourists from the aforementioned region.

\subsection{Emergency management}

- Respondents were asked to explain to what extent their hotels were prepared for emergencies in the past and how they manage and overcome emergencies.

Respondents from Jordanian five star hotels revealed that after Amman bombings 2005 they do a lot of preparation, fix new devices, conduct emergency training, and manage their emergency plans. At the same time respondents from four and three star hotels complain about insufficient fund, high 
tax, and high price and low quality of purchased devices furthermore, poor maintenance of security devices. Also, they have difficulties when hiring security employees in the matter of the financial situation and management. Respondents also mention the decrease number of tourists visiting Jordan in the last few years, which affect the hotel industry and threaten the business and employees, and unfair competition among hotels from different star rates. Managers suffered from middle and low spender guests from different background and low experience dealing with hotels and its assets.

Respondents from Malaysian hotels also were asked how they managed and recovered from these disasters, and how they used emergency planning to return back to normality. Respondents asserted that the government introduced marketing campaigns to promote Malaysia like "Cuti Cuti Malaysia" to convince domestic tourists. Also, the government start to give the citizen paid leave if they want to travel domestically. Furthermore, produce different tourism product like agro-tourism, rural tourism, and home stay. Hotels also start to attract domestic tourists by providing massive discounts, especially in low seasons, in the weekdays, and during disasters to compensate the shortage of outbound tourism. The majority of respondents agreed that marketing campaign strategies undertaken have a very strong influencing others to visit Malaysia such as "Visit Malaysia year", "Malaysia truly Asia", and "Malaysia my second home". This publicity fosters the recovery process, and gives the confidence to the tourist to return back to Malaysia. Other strategies have been used to recover from the disasters such as increasing the service quality, hotel renovation, tax reduction, and cheap tour packages. Confirmed by respondents from industry who stated that marketing recovery campaign's efforts had made a difference, and was very important to sustain the business. Results suggest that majority of respondents support the government marketing campaigns following disasters.

- Respondents were asked about factors contribute to successful emergency planning in the hotel industry.

The finding shows that Jordanian hotels lack of strategies that contribute to successful planning in order to mitigate and prevent the negative impact of emergencies. The findings also clarified the great dependence from hotels on governmental security agents and related organizations, while some emergency plans are still not implemented or neglected by hotels. This should fill in the gap to explain why Jordanian hotels are still vulnerable to emergencies, the same findings were discussed by Sawalha, Jraisat [36] study on disaster management best practices. The emergency management literature provides a wide range of frameworks and strategies to be adopted from hotel management to mitigate the impact of natural and man-made emergencies. Jordanian hotels seem to have a problem in the practical implementation of such strategies, focusing on pre-emergency period rather than proemergency period. Therefore, Jordanian hotels should adopt one or more emergency planning frameworks to improve safety and security.

Respondents discussed factors that could contribute to successful emergency planning in Jordanian hotels. Effective collaboration between hotels and share important information to update their plans, evaluate it regularly and continuous audit. The findings also emphasized the important role of effective free training within the hotels and with related organizations, clarified the important role of civil defense to spread the right knowledge about plans and security systems which meet the international standards, and help the hotels in fixing the systems, test it, and identify the role of emergency employees in the case of events. Respondents also shed the light on the importance of providing electric generator in the case of blackouts, and four wheel vehicle in the snow storms. Also, provide the handicap facilities to facilitate their stay in the hotel and to ease their evacuation in emergencies.

Respondents from local and regional Malaysian hotels confessed that they don't have any emergency planning for disasters. They argued that they implemented some recovery strategies in the past with no impact, as they overshadowed by the negative impact of disasters especially with the negative role of media coverage. Respondents who don't have proactive planning and recovery strategies reported that they don't want to do such kind of planning if the disaster will occur again, and conclude that "we don't have sufficient resources", "our work is too small" and "what we can do in the face of disasters". While, other respondents from International hotels reported that they have 
emergency planning for disasters and hazardous events. Few of them have formal written plans, and other noted that they develop non documented plans. This will give an indication that bottom-up to emergency proactive planning is not effective, since some respondents seem unwilling to develop their own proactive plans. Further questions to the respondents about the contents of their written plans, around half of them report that their plans are "general" or merely "fire and evacuation plans". And a quarter of the respondents listed two or more emergency planning scenarios to deal with emergencies and recover from disasters.

\section{Conclusion}

Jordan and Malaysia have subsequently been struck by a range of disasters and emergencies. Reflecting the hotels vulnerability to hazardous events in the internal and external environment, they have caused dramatic fluctuations in Tourist arrivals and revenue. Events discussed in this research disclose a wave of disasters affecting the hotels over the last few decades, which affects this industry contribution to GDP and reveals the multiplier effect on the economy. The finding also emphasizes that the organization type, age, and size had a great effect on proactive planning and whether if the organization faced a disaster before. Also, emphasizes the power of media in clearing the ambiguity, which helps marketing efforts towards tourists to change their attitudes and visit Malaysia rather than visiting hazardous destinations. Preparedness and an updated emergency plan with managers' awareness will help the hospitality industry to provide the necessary resources, as well as effective training to avoid or minimize risks. Safety surveillance and security systems are very important to save guests' lives and hospitality properties. These factors can also be used as a marketing tool for guests and meeting planners. Proactive emergency planning and the urgent need for better cooperation, coordination and awareness efforts among the industry stakeholders, government agencies, and local communities could mitigate the negative impact of hazardous events, allowing organizations to learn from the past to prevent the same effects in the future. Finally, it's very important to understand the emergency frameworks to mitigate effects and be well prepared before the crisis strike, and furthermore, to minimize losses during evacuation when the disaster happens. Effective proactive planning was exists in the governmental level, increase awareness, enhance services, secure sufficient fund, emergency planning knowledge will help the industry to be well prepared for future disasters. Learning from the past to overcome the effect of such events. But unfortunately, this study found a dereliction to proactive emergency planning by the industry key players.

\section{Acknowledgments}

The authors would like to extend their appreciation to the Universiti Sains Malaysia for the Research University Grant under the Sustainable Tourism Research Cluster entitled 'Tourism Planning' [Grant No. 1001/PTS/8660013] which made this study and paper possible.

\section{References}

1. I.I. Mitroff, Crisis leadership: Planning for the unthinkable. John Wiley \& Sons Inc.(2004)

2. B. Prideaux, The Need to Use Disaster Planning Frameworks to Respond to Major Tourism Disasters. Journal of Travel \& Tourism Marketing, 15, 4, 281-298 (2004)

3. T.J. Kash and J.R. Darling, Crisis management: prevention, diagnosis and intervention. Leadership \& Organization Development Journal, 19, 4, 179-186 (1998)

4. E. Cohen, Explorations in Thai tourism: Collected case studies. Emerald Group Publishing. 11 (2008)

5. A. Gheytanch, et al., The dirty dozen: Twelve failures of the Hurricane Katrina response and how psychology can help. American Psychologist, 62, 118-130 (2007) 
6. P.W. Hystad and P.C. Keller, Towards a destination tourism disaster management framework: Long-term lessons from a forest fire disaster. Tourism Management, 29, 1, 151-162 (2008)

7. R. Perry and E. Quarantelly, what is Disaster? New Answers to Old Questions. Xlibris Press, Philadelphia, PA.(2004)

8. B. Richardson, Socio-technical disaster: profile and prevalence. Disaster Prevention and Management, 3, 4, 41-69 (1994)

9. S.H. Ali and A.F. Ali, A Conceptual Framework for Crisis Planning and Management in the Jordanian Tourism Industry. Advances in Management, (2011).

10. A. Paraskevas and B. Arendell, A strategic framework for terrorism prevention and mitigation in tourism destinations. Tourism Management, 28, 6, 1560-1573 (2007)

11. The United Nations Development Programme, Support to Building National Capacity for Earthquake Risk Reduction at ASEZA in Jordan, A.S.E.Z. Disaster Risk Management Profile, Editor: Aqaba, Jordan.(2010)

12. M. Al-dalahmeh, et al., Insights into Public Early Warning Systems in Developing Countries: A Case of Jordan. Life Sci Journal, 11, 3, 263-270 (2014)

13. M.S. Aini, A. Fakhrul-Razi, and M. Daud, Evolution of emergency management in Malaysia. Journal of Contingencies and Crisis Management, 9, 1, 46-53 (2001)

14. I.M. Shaluf, Disaster types in Malaysia: an overview. Disaster Prevention and Management, 15, 2, 286-298 (2006)

15. S.P. Low, J. Liu, and S. Sio, Business continuity management in large construction companies in Singapore. Disaster Prevention and Management,1 9, 2, 219-232 (2010)

16. J. Ichinosawa, Reputational disaster in Phuket: the secondary impact of the tsunami on inbound tourism. Disaster Prevention and Management, 15, 1, 111-123 (2006)

17. A. Cashman, J. Cumberbatch, and W. Moore, The effects of climate change on tourism in small states: evidence from the Barbados case. Tourism Review, 67, 3, 17-29 (2012)

18. D.P. Coppola, Introduction to International Disaster Management. Elsevier Science.(2010)

19. C. Pforr, Tourism in post-crisis is tourism in pre-crisis: A Review of the Literature on Crisis Management in Tourism: School of Management, Curtin University of Technology.(2006)

20. B. Rittichainuwat, Understanding perceived trvel risk differences between first time and repeat travelers. in 3rd global summit on peace through tourism-education forum: one earth one family: Travel \& Tourism-serving a higher purpose. Pattaya, Thailand. (2005)

21. Y. Mansfeld, The role of security information in tourism crisis management: the missing link. Tourism, Security \& Safety: From Theory to Practice, Butterworth-Heinemann, Oxford, 271-290 (2006)

22. I. Helsloot and A. Ruitenberg, Citizen response to disasters: a survey of literature and some practical implications. Journal of Contingencies and Crisis Management, 12, 3,98-111 (2004)

23. D. Alexander, Principles of emergency planning and management. Oxford University Press, New York, USA.(2002)

24. D. Alexander, Towards the development of a standard in emergency planning. Disaster Prevention and Management, 14, 2, 158-175 (2005)

25. D.T. Crews, The case for emergency management as a profession. Australian Journal of Emergency Management, 16, 2, 2-3 (2001)

26. R. Perry and M. Lindell, Preparedness for emergency response: guidelines for the emergency planning process. Disasters, 27, 4, 336-350 (2003)

27. D. Paton, Disaster preparedness: a social-cognitive perspective. Disaster Prevention and Management, 12, 3, 210-216 (2003)

28. K.A. Stahura, et al., Emergency planning and recovery for terror situations: an analysis with special reference to tourism. Worldwide Hospitality and Tourism Themes, 4, 1, 48-58. (2012)

29. Dynes, R., "Coming to terms with community disaster", in Quarantelli, E.L. (Ed.), what Is a Disaster? Perspectives on the Question, Routledge, London, 109-126 (1998)

30. C. Chaudhary, Research Methodology. Jaipur: S. K. Parnami, R. B. S. A. Publishers. 234. (1991) 
31. R.W. Riley and L.L. Love, The state of qualitative tourism research. Annals of Tourism Research, 27, 1, 164-187 (2000)

32. A.H. Walle, Quantitative versus qualitative tourism research. Annals of Tourism Research, 24, 3, 524-536 (1997)

33. M. Sandelowski, Sample size in qualitative research. Research in nursing \& health, 18, 2, 179$183(1995)$

34. M.L. Patten, Understanding research methods: An overview of the essentials. Pyrczak Pub. (2007)

35. B. Ritchie, Chaos, crises and disasters: a strategic approach to crisis management in the tourism industry. Tourism Management, 25, 6, 669-683 (2004)

36. I.L. Sawalha, Jraisat, and K. Al-Qudah, Crisis and disaster management in Jordanian hotels: practices and cultural considerations. Disaster Prevention and Management, 22, 3, 210228.(2013) 